\title{
REFLEXIONES EN TORNO A CINE Y REGIÓN: EL CINE ARGENTINO DESDE UNA PERSPECTIVA LOCAL
}

\author{
Ana Laura Lusnich* \\ https://orcid.org/0000-0001-6612-4864 \\ Alicia Aisemberg** \\ https://orcid.org/0000-0003-3063-9369
}

\section{Introducción}

El crecimiento del cine producido en contextos regionales, desde fines del siglo XX y en las dos primeras décadas del nuevo milenio, impulsó la apertura de nuevas indagaciones teóricas e históricas que, sin contar con una significativa tradición crítica, apuntaron a reformular el concepto clásico del denominado regionalismo y apostaron a generar una legitimación de las escrituras cinematográficas de la Argentina. Así, un conjunto de trabajos aún incipiente ha colaborado con la visibilidad del cine perteneciente a las distintas regiones, provincias y localidades en el mapa nacional, del mismo modo que se ha destacado por exponer nuevas propuestas y criterios para abordar el tema mediante una perspectiva regionalizada. Los aportes realizados en los últimos años por Mohaded (1988), Etchenique y Pena (2003), Beceyro (2014) y Brunetti (2016) -entre otros estudiosos que enfrentaron estos desafíos-, y las reflexiones más amplias y colectivas concretadas en los dosieres coordinados por Barrios y Arancibia (2017; 2018), Lusnich y Campo (2018), y Flores (2019), junto con el libro compilado por Kriger (2019), expresan no solo el interés por valorizar el patrimonio cinematográfico y audiovisual gestado en la Argentina por fuera de las zonas más productivas y estudiadas —nos referimos al Área Metropolitana de Buenos Aires (AMBA)—, sino también la decisión de indagar histórica y críticamente en torno a las formas de producción, los modos de representación, las estrategias de distribución y de exhibición. Bajo estos parámetros, entre los trabajos iniciales, los escritos de Jorge Etchenique y Cristhian Pena (sobre La Pampa) y Ricardo Brunetti (dedicado a Tucumán) contribuyeron con el análisis de la presencia temprana y constante del cine en ambas provincias, en lo que corresponde a la exhibición de films y a la configuración de un "nuevo espacio" de encuentro social, en el que el entretenimiento, la promoción cultural y/o la

* Consejo Nacional de Investigaciones Científicas y Técnicas (CONICET) - Centro de Investigación y Nuevos Estudios sobre Cine (CIyNE), Facultad de Filosofía y Letras, Universidad de Buenos Aires (UBA), Argentina, alusnich@gmail.com

** Instituto de Historia del Arte Argentino y Latinoamericano, Facultad de Filosofía y Letras, Universidad de Buenos Aires (UBA), Argentina, aaisemberg@hotmail.com 
concientización política se vertebraron como facetas indisociables del cine. A su vez, se trata de estudios que se detienen en la producción local de films, con el propósito de relevar las primeras realizaciones y de realizar en forma paralela la búsqueda material de las cintas -objetivos dispuestos por Etchenique y Pena para los films realizados en La Pampa desde 1920 - o bien con el fin de evaluar el crecimiento sostenido del cine regional contemporáneo (según investiga Mohahed en el caso de Córdoba), que desde los 2000 incrementa la producción de largometrajes frente a la histórica producción de cortos y de mediometrajes. Beceyro (2014), por su parte, ofrece un encuadre teórico a partir de sus reflexiones acerca de la cuestión de la región en el campo del cine, sosteniendo que la categoría de cine regional debe distanciarse de una concepción restrictiva que intente señalar de modo normativo cuáles son los temas y procedimientos formales que configuran el sello distintivo de cada zona. Por el contrario, deben trascenderse todo tipo de imposiciones estéticas, exigencias narrativas y obligaciones de tópicos característicos. Con esta perspectiva Beceyro procura construir "una noción sana de región":

Porque la región, o la zona, proporciona a los artistas, sean escritores o cineastas, los materiales básicos con los cuales trabajar sus films o sus narraciones. Estos materiales son los lugares, calles, playas, plazas, los atardeceres, las salidas de sol, la lluvia y los calores, e incluso quizá el ámbito particular en el que se anudan y desatan los sentimientos, los conflictos, las tensiones, las crisis entre los seres humanos, que de esa manera quizá puedan adquirir un tono, un carácter propio. Estas son las particularidades de la región que legítimamente alimentan la cultura, la práctica artística (Beceyro, 2014, p. 20).

En tanto, los dosieres y compilaciones mencionados coinciden en otorgar nuevas coordenadas espacio-temporales y herramientas crítico-reflexivas a la dimensión regionalista, lo que abarca la opción "de reflexionar en torno a la diversidad y de igual manera a la integración de las diferentes regiones, entendiendo que cada una de ellas ha conformado su campo cinematográfico en función de motivaciones internas propias, y a su vez, de las relaciones de poder y/o de colaboración tejidas con el centro político-económico del país" (Lusnich y Campo, 2018, p. 2). Estas metas se alcanzan incursionando en la metodología de los estudios comparados, o bien propulsando problemas de investigación que atraviesan las fronteras provinciales y/o regionales particulares. De esta manera, los artículos que componen esos monográficos y compilaciones se enfocan en fenómenos más amplios, como son el devenir histórico del campo cinematográfico en las distintas regiones del país, la incidencia de las políticas culturales y cinematográficas en diferentes períodos en los procesos de centralización y de descentralización de la producción cinematográfica y audiovisual, la reflexión en torno a los modos de producción y la interpretación del rol cumplido por los avances tecnológicos, las disputas desplegadas por las representaciones regionales, y la 
incidencia de los festivales gestados por fuera del AMBA en la circulación de los films en sus provincias entre los aspectos más convocantes.

Creemos, entonces, en la necesidad de ampliar y consolidar las investigaciones en torno a la cuestión cine y región, mediante el desarrollo de relevamientos exhaustivos y reconfiguraciones críticas, con el fin de pensar la historia del cine argentino desde una perspectiva local. El aporte de estos estudios consistirá en reflexionar acerca de las condiciones particulares de producción, difusión y construcción estética en lugares no centrales, en vinculación y/o en tensión con los centros culturales y cinematográficos. En esta misma línea, es relevante considerar el desarrollo de formas de interrelación regional (lo que abarca las regiones y los países fronterizos), cuyos vínculos asociativos siempre existieron pero no fueron suficientemente estudiados. En este sentido, nos interesa adoptar el enfoque propuesto por Heredia (2012) para el estudio de la literatura argentina regional, en el que destaca que no habría que restringirse sólo al vínculo colonizado por la región central, sino también focalizar la investigación en el desarrollo de redes entre regiones igualmente relegadas a la periferia. Consideramos que la renovación a nivel estético, tecnológico y de las prácticas productivas de los cines regionales contemporáneos de la Argentina tuvo un efecto dinamizador en el campo de los estudios de cine con una perspectiva regionalizada. No obstante, no se debe dejar de destacar que la emergencia y el desarrollo de los cines locales poseen una dimensión histórica que según cada caso se remonta a las primeras décadas, al cine clásico-industrial y a los años sesenta o setenta. Esta producción deslegitimada y oculta, tuvo momentos excepcionales de mayor visibilidad como fue el caso del cine de Santa Fe en los 60, pero en su gran mayoría mantuvo una ubicación marginada en el mapa nacional de los bienes culturales. Por lo tanto, en lo relativo al posicionamiento de la investigación es determinante adoptar una perspectiva histórica de los procesos regionales, los cuales poseen sus peculiaridades y matrices identitarias, sin restringir los estudios al fenómeno de la producción contemporánea y apartándonos de nociones perimidas como la del regionalismo tradicional, cuya concepción — vinculada al nativismo y al costumbrismo - fue construida por el nacionalismo y su proyecto de homogeneización cultural, desde la primacía hegemónica del centralismo (Heredia, 2012).

La adopción de un estudio de las dinámicas históricas regionales nos permite comprender los sucesivos posicionamientos en el mapa, el desarrollo de polos productivos, el surgimiento paulatino de los campos cinematográficos locales y el tejido humano e institucional comprometido en esas configuraciones. Asimismo, es posible estudiar las formas estéticas que se fueron instalando y permitieron edificar representaciones que luego conformaron sus propias genealogías y fueron referentes de cada región, también construidas a partir de los intercambios, préstamos y apropiaciones con otras representaciones circulantes. Esta línea de investigación se propone estudiar los repertorios y las estrategias representacionales, así como las luchas entre distintos modos de configurar las imágenes, teniendo en cuenta, tal como sostienen en su estudio Arancibia y Saavedra (2018), el espesor histórico de las imágenes constituidas en el transcurso de la historia audiovisual local y su pervivencia en las subjetividades de la región. Por ello, resulta determinante el análisis de las pujas desarrolladas por las 
representaciones locales que apuestan a distanciarse de las imágenes cristalizadas que responden a discursos hegemónicos. En este sentido, las nuevas investigaciones que adoptan una perspectiva regionalizada destacan: "La producción audiovisual de las regiones del país que tratan de no reproducir las lógicas centralistas ni las matrices productivas impuestas enfrentan el desafío de fisurar las representaciones instauradas, de des-ocultar discursos y poner a circular ciertas imágenes invisibilizadas y voces silenciadas" (Barrios y Arancibia, 2017, p. 28).

Bajo estos parámetros generales, los trabajos que integran el presente dosier ${ }^{1}$ proponen tres enfoques diferenciados mediante los que se pretende lograr una aproximación a las distintas aristas del cine regional desde una perspectiva históricocrítica actualizada que contempla la larga duración histórica, las configuraciones locales, provinciales y regionales, y las interrelaciones existentes entre las diferentes regiones. El primer lineamiento de investigación busca visibilizar la configuración de los distintos modos de producción que se desplegaron en la historia del cine regional hasta el presente y su dinamización a partir de la creación de ámbitos de formación locales. La segunda perspectiva de estudio apunta al análisis textual de prácticas representativas regionales. En tercer lugar, a partir del estudio de publicaciones críticas y periodísticas que se focalizan en el cine producido en las regiones, se pretende examinar el desarrollo histórico de las reflexiones dedicadas al cine regional.

La primera aproximación crítico-reflexiva que proponemos tiene como finalidad ahondar acerca de las modalidades y sistemas de producción que las cinematografías de la Argentina situadas por fuera del AMBA han desplegado a lo largo del tiempo, con el compromiso - según los casos - de realizadores que gestionaron sus propios esquemas de producción, grupos, colectivos, e instituciones públicas y privadas. Si hasta hace poco tiempo las formas de producción desarrolladas en el país se clasificaban en dos categorías (industrial e independiente) determinadas cada una de ellas por la mayor o menor durabilidad de las empresas y el tipo de film realizado (Getino, 1998), los relevamientos e investigaciones consolidados en los últimos años llevan a sostener que los sistemas de producción se ajustaron a procesos de mayor concentración y a otros de visible expansión, determinados por las coyunturas políticas, económicas y culturales regionales y nacionales ${ }^{2}$. En simultaneidad, la clásica dicotomía industrialindependiente que a los aspectos ya mencionados sumaba la asociación de lo industrial al AMBA y de lo independiente a las otras localidades de nuestro territorio con menos recursos e infraestructura comenzó a ser reinterpretada, identificándose focos de producción industrial en diferentes regiones del país (Santa Fe en el período silente

\footnotetext{
1 Los autores del dosier integran el proyecto de investigación actualmente en curso "Cartografía y estudio histórico de los procesos cinematográficos en Argentina", financiado por la Secretaría de Ciencia y Técnica de la Universidad de Buenos Aires y la Agencia Nacional de Promoción Científica y Tecnológica.

2 En líneas generales, los historiadores y críticos situaron en los años sesenta el primer proceso de descentralización de la producción cinematográfica argentina, con la actividad generada en la provincia de Santa Fe con el liderazgo de Fernando Birri, realizador-formador-gestor que impulsó un proyecto local de producción, distribución y exhibición. Sin embargo, como ya se ha anticipado en esta Introducción, es necesario reinterpretar con estos mismos objetivos las décadas previas, en las cuales se observan desarrollos que pretendieron impulsar y posicionar las cinematografías locales.
} 
y de transición al sonoro; Mendoza entre mediados de los años 40 y 50; San Luis y Córdoba desde el 2000). De igual modo, se comenzaron a detectar y a conceptualizar otros esquemas de producción localmente arraigados y significativos, entre los cuales se destacan la producción encaminada por colectivos y comunidades, por los centros de formación y a partir de la asociación de empresas productoras bajo el formato de Clúster o conglomerado de empresas geográficamente próximas, entre las principales vertientes. De acuerdo con estas nuevas perspectivas de análisis que afianzan las ideas de la diversidad y convivencia de múltiples modalidades de producción de forma manifiesta en la actualidad, pero también visible en etapas previas de la cinematografía nacional), los artículos de este dosier profundizan en torno a una serie de situaciones particulares: la impronta industrial de la firma mendocina Film Andes en los años 40 y 50, el pasaje del cine amateur al profesional-independiente en la provincia de Chaco en los años 60 y 70, el cine comunitario de la Provincia de Buenos Aires y su expansión interregional e internacional, y la consolidación de las escuelas de cine de la Patagonia con su consiguiente incidencia en la formación de profesionales del sector y en el impulso de la producción regional.

Enfocándose en el entrecruzamiento de lo regional y lo industrial, Alejandro Kelly Hopfenblatt se dedica a estudiar la compañía productora mendocina Film Andes creada en el transcurso del periodo clásico. La empresa construyó sus propios estudios de filmación, e implementó estrategias de distribución y de exhibición comercial según el modelo de Buenos Aires, con el objetivo de desarrollar tópicos locales e internacionales. En relación a este último aspecto, el autor identifica una tensión constitutiva entre cosmopolitismo y localismo que atravesó a las distintas producciones, puesto que pretendían equilibrar una lógica comercial de acuerdo a los modelos de las cinematografías globales y a la vez construir una representación ligada a lo regional. A la hora de abordar la problemática resultan determinantes un conjunto de factores delineados por el autor, que demuestran la particularidad del proyecto mendocino y la complejidad de su categorización. En un sentido, la productora Film Andes puede pensarse en relación con otros proyectos de dimensión regional del periodo, pero, a su vez, es necesario diferenciarla por su magnitud y sus características de producción. En base a estos criterios se encara un estudio pormenorizado de las diversas etapas atravesadas por la compañía y de las características de las películas, que intentaban aunar los modelos de los géneros industriales y los rasgos de la identidad mendocina a través de los escenarios, temas y la participación de intérpretes locales en roles secundarios.

Centrando su estudio en la provincia de Chaco en el período 1960-1976, Franco Passarelli analiza dos aristas del incipiente campo cinematográfico de la región Nordeste del país. Por un lado, se enfoca en el circuito de producción independiente que tuvo centro en esos años en la ciudad de Resistencia, producto de las interrelaciones trazadas por un conjunto de realizadores y el estímulo de la Universidad Nacional del Nordeste. En segundo lugar, avanza en la interpretación de las formas narrativas y espectaculares entonces predominantes, conceptualizando dos categorías de análisis: el "cine científico" y el "cine de la diferencia" (o alteridad). El estudio de las trayectorias de los 
realizadores chaqueños y de los films producidos permite observar los posicionamientos de esta etapa. Entre otros puntos, en los años estudiados subraya el autor el NEA sostuvo relaciones e intercambios interregionales que implicaban dinámicas enriquecedoras (la formación universitaria del director chaqueño Jorge Castillo en Rosario y la radicación del santafesino Juan Carlos Vidarte en la provincia ratifican esta idea). A ello habría que agregar que una característica del período fue el pasaje del amateurismo a la consolidación profesional de su actividad.

El artículo de Jimena Cecilia Trombetta aborda un fenómeno contemporáneo que, circunscripto inicialmente a la localidad de Quilmes con la creación del realizador José Celestino Campusano en 2006 de la productora Cinebruto, y su ejercicio del cine comunitario en esas fronteras espaciales, en la década siguiente se expande a toda la provincia. Esto ocurre en 2013 con la fundación en 2013 del Clúster Audiovisual de la provincia de Buenos Aires (CAPBA) y sus primeros festivales locales-, para inmediatamente alcanzar proyecciones interregionales e incluso internacionales. De acuerdo con lo expuesto por la autora, más allá del salto cualitativo que implicó el pasaje de la producción comunitaria centralizada en la productora de Campusano a la ramificación exponencial en lo que atañe a agentes audiovisuales y acciones emprendidas, el CAPBA y sus pares argentinos y extranjeros mantuvieron la apuesta y los fundamentos de un cine comunitario. Jimena Trombetta no disocia los modos y sistemas de producción analizados de las formulaciones textuales concretadas en esos espacios colaborativos, destacando que se han enfocado en plasmar problemáticas y voces emergentes (relacionadas con el maltrato laboral, la exclusión social, la discriminación de género). Incluso, las coproducciones realizadas con países del continente americano (Bolivia, México, Estados Unidos) no se distancian de estos objetivos primordiales, exponiendo las temáticas de las migraciones, el racismo y las diferencias de clase.

En lo referido a la investigación de Silvana Flores y Julia Elena Kejner, el estudio se focaliza en el desarrollo de las carreras terciarias y universitarias dedicadas al audiovisual en la región patagónica, y las transformaciones que generaron en el campo cinematográfico local. Este enfoque permite indagar acerca de la intensificación de la profesionalización de los cineastas a partir del desarrollo de ámbitos de formación local, así como también apunta a analizar el efecto de dinamización generado en la producción cinematográfica de la región. Las autoras abordan el problema delineando tres momentos del proceso desarrollado en la Patagonia: una primera etapa (1960 a 1989) en la que aún se ofrecía una escasa formación, que era suplantada por otras prácticas de capacitación y el traslado hacia otras regiones; un segundo momento (1990-2009), que fue fundacional en relación al surgimiento de las primeras carreras especializadas; y un tercer decenio (2010-2020), que estuvo signado por el incremento de espacios educativos en cada provincia de la región. De este modo, el trabajo traza una revisión pormenorizada de los diferentes factores que tuvieron incidencia en las sucesivas transformaciones del fenómeno educativo del audiovisual, entre los que se identifican las búsquedas de dinamización económica y turística de la región, y la productividad que tuvieron las políticas audiovisuales nacionales de carácter federal y de los estados subnacionales. 
En este aspecto, según destaca el estudio aquí presentado, se tornan sustanciales los procesos de federalización de la última década, los cuales favorecieron el desarrollo de instituciones de educación audiovisual en las provincias y, a su vez, potenciaron la producción regional, generando una retroalimentación entre ambos.

El segundo eje de investigación propuesto aborda el análisis de las prácticas representativas de los films regionales, distanciándose de una visión esencialista y evitando adoptar una concepción restrictiva de lo regional en cuanto a consignar tópicos característicos o aspectos formales distintivos para cada zona. Lo que intentamos plantear, por el contrario, apunta a establecer un análisis de las estrategias representacionales considerando su heterogeneidad y adoptando una concepción dinámica de las identidades de las regiones del país. Las múltiples modalidades de figuración regional construyen alternativas con respecto a las representaciones hegemónicas, reivindicando las marcas de la región. Por ello mismo, se toma distancia de la impronta de un regionalismo costumbrista de carácter remanente y de cuño centralista, y se buscan otros modos de inscripción de las huellas del lugar de enunciación regional (Heredia, 2007). Estas modalidades representacionales - distantes de caracterizaciones de un supuesto color local - proponen otras formas de percepción de los "materiales locales" que nutren a los cines regionales, visibilizando otros lugares e identidades. No obstante, debemos considerar que los rasgos regionales se entrecruzan con otros discursos, representaciones y estructuras narrativas, estableciendo relaciones intertextuales con modelos legitimados, mediante intercambios y apropiaciones tanto de elementos procedentes de los géneros como de los proyectos autorales. Las marcas regionales inscriptas en las películas se evidencian en la construcción de la imagen y en la puesta en escena. En este aspecto cobran valor determinadas formas de plasmar el espacio que expresan una percepción particular sobre lo urbano, las zonas rurales y los paisajes naturales. A su vez, la incorporación de actores procedentes de las provincias tanto con formación como no profesionales permite explorar formas genuinas en lo relativo a las representaciones sociales locales, colaborando con la búsqueda de una voz y de un tono propio de la zona sin caer en estereotipos ajenos. Como sostienen Barrios y Arancibia (2017), es determinante el análisis de las representaciones alternativas de las regiones del país propuestas en los films, que establecieron una disputa cultural con las visiones centralistas y revelaron otro tipo de imágenes, voces y sonidos.

Dos escritos integran nuestra presentación monográfica con la intención de reflexionar sobre la cuestión de las estrategias de representación de los cines regionales del país. El trabajo de Jorge Sala se dedica al examen de dos films de los primeros años de la producción de Miguel Pereira en el contexto del cine testimonial de la transición democrática, con una particular significación en tanto instauraron el cine de ficción de la provincia de Jujuy. El análisis del autor apunta a pensar las formas en que los films entrecruzan las problemáticas regionales y las referidas al contexto político e histórico nacional. Con ese objetivo, busca focalizarse específicamente en el modo de construcción del espacio, dado que entiende que allí se condensan las marcas de lo regional en relación y en tensión con la representación del espacio de lo nacional. 
Dicotomía que se plantea mediante el tratamiento de la oposición rural-urbano y a partir del recurso cinematográfico de la relación entre el campo y el fuera de campo. Por ello mismo, su análisis se sustenta en las concepciones que reflexionan sobre el paisaje y el espacio como lugares donde se sitúan no sólo determinaciones estéticas sino también históricas y políticas. En la aproximación a La deuda interna (Miguel Pereira, 1988) el trabajo señala la centralidad que tuvo la decisión de revisar el pasado dictatorial desde una óptica periférica, que de este modo problematizaba la existencia de una única visión de los conflictos históricos impuesta desde Buenos Aires. A su vez, en ambos films, según advierte el presente artículo, se irá profundizando la intención de dar a conocer lugares con escasa visibilidad en la cultura audiovisual.

Por su parte, Iván Morales realiza un análisis de la película salteña Badur Hogar (Rodrigo Moscoso, 2019), cuya singularidad según indica el autor radica en apropiarse del género de la comedia romántica para narrar una historia local, además de practicar otras estrategias distintivas como la de situar el relato en el espacio urbano de la capital con la intención de apartarse de una visión petrificada de lo regional y de una repetición epigonal de las caracterizaciones pintoresquistas. El artículo examina las tensiones entre las representaciones dominantes de la provincia portadoras de una concepción afín al tradicionalismo cultural y las figuraciones alternativas — desarrolladas a fines del siglo $\mathrm{XX}$ y en las dos décadas del XXI- vinculadas mayormente a formas rupturistas y con una particular productividad estética en el campo cinematográfico local y del país. En este contexto, según advierte el autor, el film de Rodrigo Moscoso aspirará a ofrecer otros caminos en lo relativo a las luchas representacionales centro-periferia, al vincularse tanto a formas narrativas industriales y populares como a entornos de la urbanidad. El análisis posiciona al film en un entramado complejo de tradiciones representacionales circulantes que incluyen tanto a las visiones turísticas o tradicionalistas de la cultura salteña como el estilo codificado del cine independiente que en parte responde a criterios de los festivales. Rodrigo Moscoso opta por otra posibilidad que es la de recurrir a estrategias de la comedia y, en definitiva, apostar a un cine de género que asuma una perspectiva local, sin dejar de dar cuenta de las tensiones sociales.

Finalmente, el tercer enfoque planteado se circunscribe al análisis de una serie de publicaciones tempranas que, especializadas en el medio cinematográfico o dedicando un segmento de sus páginas al mismo, se enfocaron en aspectos propios de los cines regionales de la Argentina. Los medios gráficos cumplieron un rol determinante en el consumo cultural y cinematográfico, promocionando films internacionales y nacionales, y de igual modo "instruyendo" a las audiencias en el mundo del cine, en su imaginario y sus narrativas, más allá de impulsar los procesos de producción, distribución y exhibición de los films. Además, acompañaron y potenciaron proyectos autorales y/o colectivos como han sido los de los años 60 y 90 siendo históricamente un "discurso instituyente" que ha prestado atención a las transformaciones culturales (Moguillansky y Re, 2006). En esta oportunidad, los artículos aquí publicados coinciden en explorar el territorio de las publicaciones críticas y periodísticas que se enmarcan en las dos primeras etapas de la crítica cinematográfica argentina, la primera asociada a la emergencia del nuevo 
fenómeno técnico-artístico; la segunda a los procesos de la industrialización definitiva del cine (Kriger, 2003).

Mediante un relevamiento hemerográfico profundo y la interpretación crítica de las fuentes primarias, ambos trabajos se detienen en la comprensión de las visiones que los editores y/o redactores formulan en torno al medio cinematográfico y a su constitución a nivel regional. El estudio de estas publicaciones permite contrastar las ideas que con el paso de los años se gestaron en torno a la distribución de films (nacionales y extranjeros) y al trazado de circuitos de exhibición regionales e interregionales, la conformación de imaginarios afines a las realidades locales, y las pujas y/o relaciones que se avizoraron entre la ciudad capital y las otras regiones del país.

Cuarterolo y Jelicié reconstruyen la trayectoria y las actividades de Alejandro Del Conte, que en 1916, por un período de cuatro años, se radica en San Miguel de Tucumán. Los autores sostienen que se trata de una personalidad que transforma el escenario cinematográfico y cultural de Tucumán y de todo el norte argentino, por su actividad desplegada en el campo de la producción, la distribución, la exhibición y la crítica cinematográfica regional. Centrando su estudio en el primer medio gráfico especializado de la región norteña Film Gráfico. Revista Semanal Cinematográfica del Norte de la República, editada en 1917 y 1918, creada y dirigida por Del Conte, los autores desbrozan las acciones desplegadas por este singular "agente cinematográfico" que se propone dos metas centrales: valorizar el carácter educativo e informativo del medio cinematográfico y desarrollar un proyecto descentralizado en lo que corresponde a la distribución y exhibición de películas. Como explican Cuarterolo y Jelicié, instalar la periferia como centro de comercialización y de exhibición de films implicó para Del Conte intervenir de forma activa en la conformación del campo cinematográfico norteño. Su rol como director de Film Gráfico y sus esfuerzos por contribuir en la constitución de un circuito comercial regional situado en la ciudad de Rosario lugar con quien traza fuertes vínculos con agencias distribuidoras y alquiladoras de películas demuestran su afán en la regionalización de la actividad cinematográfica.

Grela Reina y Peterlini, por su parte, se enfocan en un segmento de publicaciones periódicas especializadas editadas en la ciudad de Buenos Aires en el período 1914-1959. Las mismas poseen secciones, notas y crónicas sobre las actividades cinematográficas a nivel regional, relevadas del acervo que posee la Biblioteca Nacional de la República Argentina Mariano Moreno. Más allá de posibles preconceptos relacionados con la falta de conocimiento de las realidades locales y/o con la conjetura de que los editores de Buenos Aires bregaban por sostener el marcado centralismo político y cultural de la metrópolis, las autoras analizan las formas en que estas revistas se implican y comprometen con las actividades cinematográficas de todo el país. Sin desconocer que la prioridad de todas ellas ha sido sin embargo la difusión de los films europeos y norteamericanos, y los procedentes de Buenos Aires. Las publicaciones producen noticias y crónicas que permiten recomponer el panorama cinematográfico regional aportando información sobre una amplia serie de fenómenos del período silente y del clásico-industrial exponiendo la existencia de un territorio fértil y con dinámicas propias. 


\section{Referencias bibliográficas}

Arancibia, V. \& Saavedra, M. (2018). "Las construcciones de las imágenes de Salta. Articulaciones entre noticias y ficciones cinematográficas". Folia Histórica del Nordeste, 31, 98-119. ISSN 0325-8238. Recuperado de: http://dx.doi. org/10.30972/fhn.0312912.

Barrios, C. \& Arancibia, V. (2017). "Introducción. Disputas culturales: producción audiovisual y configuración de las regiones en Argentina". Folia Histórica del Nordeste, 30, 53-64. ISSN 0325-8238. Recuperado de: http://dx.doi.org/10.30972/ fhn.0302722.

Beceyro, R. (2014). Cine y Región. Ensayos, proyectos y películas. Paraná: Universidad Nacional de Entre Ríos; Santa Fe: Universidad Nacional del Litoral.

Brunetti, R. (2016). Cien años de cine en Tucumán. Tucumán: Ediciones del parque.

Etchenique, J.; Pena, C. (2003). Apuntes para una historia del cine en el Territorio Nacional de La Pampa. Santa Rosa: Departamento de investigaciones culturales del Ministerio de Cultura y Educación.

Flores, S. (2019). "La producción regional en el cine argentino y latinoamericano". Imagofagia, 20, 279-298, ISSN 1852-9550. Recuperado de: http://www.asaeca. org/imagofagia/index.php/imagofagia/article/view/1935.

Getino, O. (1998). Cine argentino. Entre lo posible y lo deseable. Buenos Aires: Ciccus. Heredia, P. (2007). "Regionalizaciones y regionalismos en la literatura argentina. Aproximaciones a una teoría de la región a la luz de las ideas y las letras en el siglo XXI". En Castellino, M. E. (coord.), Literatura de las regiones argentinas II. Mendoza: UNCuyo, 155-182.

Heredia, P. (2012). "Propuestas para un estudio de las operaciones políticas de regionalización cultural en la literatura argentina". En Massara, L.; Guzmán, R.; Nallim, A. (dirs.), La literatura del noroeste argentino. Reflexiones e investigaciones, Volumen II. San Salvador de Jujuy: Universidad Nacional de Jujuy, 19-34.

Kriger, C. (comp.). (2003). Páginas de Cine. Buenos Aires: Archivo General de La Nación.

Kriger, C. (comp.) (2019). Nueva cartografía de la producción audiovisual argentina. New York: Peter Lang Publishing.

Lusnich, A. \& Campo, J. (2018). "El cine argentino y su dimensión regional". Aura. Revista de Historia y Teoría del Arte, 8, 2-7, ISSN 2347-0135. Recuperado de: http://www.ojs.arte.unicen.edu.ar/index.php/aura/article/view/614.

Moguillansky, M \& Re, V. (2006): "La crítica cinematográfica. Un pacto en el nuevo cine argentino". Questión, 1, 12, 1-8, ISSN 1669-6581. Recuperado de: http:// sedici.unlp.edu.ar/handle/10915/30312.

Mohaded, A. (1988). Producciones cinematográficas cordobesas realizadas entre 1956 y 1976. Córdoba: mimeo. 